\title{
Risk of overweight and obesity among migrants in Switzerland
}

\author{
Thomas Volken ${ }^{*}$, Peter Rüesch
}

School of Health Professions, Zurich University of Applied Sciences, Winterthur, Switzerland;

*Corresponding Author: thomas.volken@zhaw.ch

Received 25 June 2012; revised 20 July 2012; accepted 30 July 2012

\begin{abstract}
We assessed the risk of overweight and obesity for six large migrant groups in Switzerland. We used population-based survey data form the Swiss Migrant Health Survey 2010 and the Swiss Health Survey 2007. The sample comprised permanent residents aged $17-64$ years $(n=14,637)$. Multivariate logistic regressions have been used to estimate odds ratios (OR). Compared with Swiss nationals, the odds of being obese were 1.97 times higher for Turkish nationals (Cl-95 1.26, 3.07), 1.73 times higher for Kosovan nationals ( $\mathrm{Cl}-951.09,2.74)$ and 3.42 times higher for Serbs (Cl-95 2.28, 5.12). The chance of being obese was not statistically different between Swiss nationals and those from Portugal, Italy, and Germany. The chance of being overweight or obese (BMI $\geq 25$ ) was higher for migrants than for Swiss nationals. The respective odds were 1.54 times higher for nationals from Portugal (Cl-95 1.13, 2.11), 2.05 times higher for those from Turkey (Cl-95 1.50, 2.78), 2.67 times higher for those from Serbia (Cl-95 1.93, 3.68), 2.68 times higher for those from Kosovo (Cl-95 2.01, 3.56), and 2.16 times higher for nationals from Italy (Cl-95 1.54, 3.02). We suggest that preventive initiatives should take into account the specific needs of migrants as well as the needs of persons with low education from all nationalities.
\end{abstract}

Keywords: Overweight; Obesity; Migrant; Switzerland

\section{INTRODUCTION}

Noncommunicable diseases, especially cardiovascular diseases, cancer, and type 2 diabetes mellitus, currently kill more people every year than any other cause of death. Studies consistently show that overweight and obesity are associated with many health risks [1-5]. A healthy body weight could help to reduce metabolic cardiovascular risk factors, i.e. high blood pressure, plasma lipids, and insulin resistance, and prevent major diseases such as cardiovascular diseases and certain cancers [6]. The reasons for overweight and obesity are complex, likely involving genetics, family history, lack of energy balance, environment, health conditions, medicines, emotional factors, age, and interactions among these factors as well as others not fully recognized $[7,8]$. Several studies find that overweight and obesity are associated with social characteristics such as education, socio-economic status (SES) or ethnicity [9-16]. The latter may be particularly important for countries with large migrant populations such as Switzerland. In 2009, migrants accounted for 1.7 million people or $22 \%$ of the permanent resident population of Switzerland [17]. Hence, migrants are an important group and prevention campaigns may need to be tailored to specific migrant groups and their needs.

A large body of literature on migration and health suggests that cultural patterns shape physical activity, body images, dietary intake and food preferences [18-24] and therefore may be associated with weight status. Several studies find that migrants have a higher prevalence of overweight and obesity $[11,14,16,25,26]$, other studies come to the opposite conclusion $[8,27]$. Based on data of the Swiss Health Survey (SHS), Marques-Vidal and colleagues have recently presented evidence that overweight and obesity are unevenly distributed among migrants in Switzerland. That is, some nationalities had a higher risk of being overweight or obese than others as compared to nationals of Switzerland [28]. SHS participants were randomly selected within private households and computer-aided telephone interviews were conducted in three of the four official national languages of Switzerland (German, French, and Italian). However, studies on migrants which are based on SHS data are potentially biased. First, interviews of the SHS were carried out in three national languages only. People who did not speak any of these languages or people who had insufficient language skills were excluded from the survey. Therefore, 
the SHS data may be biased for several reasons. The selection process potentially favours nationals from countries with the same or similar languages as Switzerland. It also favours migrants who are well-integrated, welleducated and have been living in Switzerland for a long period of time or even their entire life. Second, the SHS study population was chosen by stratified random sampling. None of the strata was referring to migration-specific properties, e.g. resident status or nationality. Consequently, the number of subjects from most nationalities other than Switzerland is quite low. The current study used data from the Swiss Migrant Health Survey 2010 (SMHS). In contrast to the SHS, participants of the SMHS were chosen by disproportional stratified random sampling and interviewed in their respective native languages in order to reduce selection bias and to improve migrant-specific sample characteristics. We estimated odds ratios (OR) of overweight and obesity among migrants in Switzerland as compared to nationals from Switzerland.

\section{METHODS}

\subsection{Study Population and Data}

Data from the SMHS 2010 and the SHS 2007 was obtained from the Swiss Federal Office of Public Health (www.bag.admin.ch). The SMHS is a cross-sectional, population-based telephonic survey which intends to monitor health trends in a representative sample of migrants and has been carried out in 2004 and 2010 so far. Due to economic constraints, the SMHS is limited to a selected number of nationalities. The core study population 2010 comprised permanent residents from Portugal, Turkey, Serbia and Kosovo $(\mathrm{n}=1800)$. Participants aged 17 - 74 were chosen by stratified random sampling (gender, country of birth, length of residence) from the database of the central immigration information system. The computer-aided telephone interviews were carried out in Portuguese, Turkish, Serbian, Albanian, German, French and Italian. Data of Swiss, German and Italian nationals from the SHS 2007 were pooled with the SMHS data. The SHS was first conducted in 1992 and is repeated every five years. The 2007 sample included over 19,000 subjects aged 15 years or older. Participants were randomly selected within private households and computeraided telephone interviews were conducted in German, French and Italian. People who did not speak any of these languages or people who had insufficient language skills were excluded from the SHS. The pooled sample represents $58.2 \%$ of the migrant population as well as nationals from Switzerland. Of the 1.7 million migrants in Switzerland, $17.0 \%$ are Italian, $14.9 \%$ are German, $12.0 \%$ are Portuguese, 5.4\% are French, 3.6\% are Spaniards, $6.9 \%$ are from Serbia, $4.1 \%$ are Turkish and $3.3 \%$ are Kosovan [29]. Migrants from France and Spain were not included because of their small sample size in the SHS. Since all interviews of the subjects in the pooled sample were conducted in their respective native language, selection bias due to insufficient language skills has been mitigated-i.e. the selection process is less likely to favor migrants who are well-integrated, welleducated and have been living in Switzerland for a long period of time. For the purpose of this study, the initial sample was further narrowed down to include only subjects 17 - 64 years old because only few migrants in the initial SMHS sample were over 64 years old. The total sample size amounts to 14,637 . The sample size by nationality and further characteristics of the pooled SMHS and SHS sample is shown in Table 1.

\subsection{Target Outcome, Predictor and Covariates}

Weight status, the target outcome of this study, was derived from self-reported weight and height and the respective body mass index (BMI) was calculated by dividing the weight in kilograms by the square of height in metres $\left(\mathrm{kg} / \mathrm{m}^{2}\right)$. Subjects were then assigned to the categories normal weight $(\mathrm{BMI}<25)$, overweight $(25 \leq$ $\mathrm{BMI}<30)$ and obese $(\mathrm{BMI} \geq 30)$. For the primary predictor, the country of origin, the following nationalities were considered: Portugal, Turkey, Serbia, Kosovo, Germany, Italy and Switzerland. However, the use of nationalities to identify migrant groups has important limitations because several migrant generations as well as several cultural groups are combined in one category.

While cultural patterns shape physical activity, body images, dietary intake and food preferences [18-24] the influence of these cultural pattern may fade over time. Several studies show that migrants often adopt the dietary practices of the host country [30-33]. Consequently, overweight and obesity of migrants in Switzerland may also be influenced by dietary acculturation [10]. In order to control for potential acculturation effects, length of time in Switzerland was added as a covariate. Further covariates included: age, gender, socio-economic status (SES) and dwelling zone (rural/urban). SES comprises three indicators: education (basic, secondary, and university), employment (economically active [no/yes]), and housing situation (rooms per person).

\subsection{Missing Data}

Missing data were generally rare on all variables. For the predictor and three covariates, no data were missing and for the remaining covariates $0.6 \%$ or less of the data were missing within each nationality. Missing data on $\mathrm{BMI}$, the dependent variable, amounted to $1.1 \%$ and there were no substantial differences in the amount of 
Table 1. Frequency distribution and central tendency for variables in the sample of subjects aged 17 - 64 years by nationality (Swiss Migrant Health Survey 2010 \& Swiss Health Survey 2007) ${ }^{\mathrm{a}}$.

\begin{tabular}{|c|c|c|c|c|c|c|c|c|c|c|c|c|c|c|}
\hline \multirow{2}{*}{$\mathrm{n}=14,637$} & \multicolumn{2}{|c|}{ Portugal } & \multicolumn{2}{|c|}{ Turkey } & \multicolumn{2}{|c|}{ Serbia } & \multicolumn{2}{|c|}{ Kosovo } & \multicolumn{2}{|c|}{ Germany } & \multicolumn{2}{|c|}{ Italy } & \multicolumn{2}{|c|}{ Switzerland } \\
\hline & $\begin{array}{l}\mathrm{n} \text { or } \\
\text { mean }\end{array}$ & $\begin{array}{l}\% \text { or } \\
\text { SD }\end{array}$ & $\begin{array}{l}\mathrm{n} \text { or } \\
\text { mean }\end{array}$ & $\begin{array}{l}\% \text { or } \\
\text { SD }\end{array}$ & $\begin{array}{l}\mathrm{n} \text { or } \\
\text { mean }\end{array}$ & $\begin{array}{l}\% \text { or } \\
\text { SD }\end{array}$ & $\begin{array}{l}\mathrm{n} \text { or } \\
\text { mean }\end{array}$ & $\begin{array}{l}\% \text { or } \\
\text { SD }\end{array}$ & $\begin{array}{l}\mathrm{n} \text { or } \\
\text { mean }\end{array}$ & $\begin{array}{l}\% \text { or } \\
\text { SD }\end{array}$ & $\begin{array}{l}\mathrm{n} \text { or } \\
\text { mean }\end{array}$ & $\begin{array}{l}\% \text { or } \\
\text { SD }\end{array}$ & $\begin{array}{l}\mathrm{n} \text { or } \\
\text { mean }\end{array}$ & $\begin{array}{l}\% \text { or } \\
\text { SD }\end{array}$ \\
\hline Sample size (n) & \multicolumn{2}{|c|}{ (449) } & \multicolumn{2}{|c|}{$(644)$} & \multicolumn{2}{|c|}{$(455)$} & \multicolumn{2}{|c|}{$(648)$} & \multicolumn{2}{|c|}{ (324) } & \multicolumn{2}{|c|}{$(369)$} & \multicolumn{2}{|c|}{$(11,748)$} \\
\hline \multicolumn{15}{|l|}{ Bmi class $(\%)^{\mathrm{b}}$} \\
\hline Normal weight & 256 & 58.1 & 373 & 59.5 & 250 & 55.5 & 380 & 60.8 & 230 & 71.4 & 180 & 49.0 & 7574 & 65.1 \\
\hline Overweight & 129 & 29.2 & 194 & 30.9 & 138 & 30.7 & 199 & 31.8 & 81 & 25.2 & 131 & 35.7 & 3172 & 27.2 \\
\hline Obese & 56 & 12.7 & 60 & 9.6 & 62 & 13.8 & 46 & 7.4 & 11 & 3.4 & 56 & 15.3 & 896 & 7.7 \\
\hline Age (years) & 35.6 & 12.2 & 33.8 & 10.5 & 33.3 & 12.4 & 29.0 & 10.7 & 40.8 & 10.7 & 43.1 & 11.9 & 43.0 & 13.0 \\
\hline \multicolumn{15}{|l|}{ Gender (\%) } \\
\hline Male & 225 & 50.1 & 322 & 50.0 & 227 & 49.9 & 322 & 49.7 & 168 & 51.9 & 204 & 55.3 & 5390 & 45.9 \\
\hline Female & 224 & 49.9 & 322 & 50.0 & 228 & 50.1 & 326 & 50.3 & 156 & 48.1 & 165 & 44.7 & 6358 & 54.1 \\
\hline \multicolumn{15}{|l|}{ Education (\%) } \\
\hline Basic & 251 & 55.9 & 259 & 40.2 & 139 & 30.6 & 303 & 46.8 & 5 & 1.5 & 92 & 24.9 & 868 & 7.4 \\
\hline Secondary & 166 & 37.0 & 246 & 38.2 & 256 & 56.4 & 323 & 49.8 & 122 & 37.7 & 228 & 61.8 & 7463 & 63.5 \\
\hline University & 32 & 7.1 & 139 & 21.6 & 59 & 13.0 & 22 & 3.4 & 197 & 60.8 & 49 & 13.3 & 3415 & 29.1 \\
\hline Economically active (\%) & 369 & 82.2 & 341 & 53.0 & 341 & 75.0 & 387 & 59.9 & 286 & 88.3 & 277 & 75.1 & 9364 & 79.7 \\
\hline $\begin{array}{l}\text { Housing situation } \\
\text { (rooms/person) }\end{array}$ & 1.1 & 0.6 & 1.2 & 0.5 & 1.1 & 0.4 & 0.9 & 0.4 & 2.1 & 1.0 & 1.8 & 1.0 & 2.0 & 1.0 \\
\hline \multicolumn{15}{|l|}{ Dwelling zone $(\%)^{\mathrm{c}}$} \\
\hline Urban dweller & 351 & 78.2 & 570 & 88.5 & 375 & 82.4 & 484 & 74.7 & 248 & 76.5 & 308 & 83.5 & 7751 & 66.0 \\
\hline Rural dweller & 98 & 21.8 & 74 & 11.5 & 80 & 17.6 & 164 & 25.3 & 76 & 23.5 & 61 & 16.5 & 3997 & 34.0 \\
\hline \multicolumn{15}{|l|}{ Length of residence $(\%)^{\mathrm{d}}$} \\
\hline$<10$ years & 223 & 49.7 & 399 & 62.0 & 219 & 48.1 & 403 & 62.2 & 202 & 63.3 & 34 & 9.7 & & \\
\hline $10-19$ years & 128 & 28.5 & 89 & 13.8 & 140 & 30.8 & 194 & 29.9 & 60 & 18.8 & 25 & 7.2 & & \\
\hline$\geq 20$ years & 98 & 21.8 & 156 & 24.2 & 96 & 21.1 & 51 & 7.9 & 57 & 17.9 & 290 & 83.1 & & \\
\hline
\end{tabular}

${ }^{a}$ Figures refer to number of subjects and percentage or arithmetic mean and standard deviation within nationality; ${ }^{b}$ Normal weight: BMI $<25$; overweight: $25 \leq$ $\mathrm{BMI}<30$; obese: BMI $\geq 30$; ${ }^{\mathrm{c}}$ Classification according to the Swiss Federal Statistical Office [44]. Urban areas include isolated cities ( $\geq 10,000$ inhabitants) and urban agglomerations ( $\geq 20,000$ inhabitants); ${ }^{\mathrm{d}}$ Number of years passed since immigration to Switzerland (non-Swiss nationals only).

missing data between nationalities. Overall, $1 \%$ of the data were missing. Our analysis of missing-value patterns revealed no systematic relations between BMI and the predictor or the covariates. We therefore assumed that the data were missing completely at random (MCAR) and applied listwise deletion which gives valid inferences under this assumption [34].

\subsection{Weighting and Standardization}

The original expansion weights of the SMHS and SHS take into account the different sampling strategies and they take into account the number of non-responders by ranking ratio estimation. However, the age and gender structure of migrant groups differs markedly from those of Swiss nationals. On average, migrants are often much younger than Swiss nationals and the proportion of males as compared to females is higher among migrant groups. Since BMI tends to increase with age and males have a higher risk of having a $\mathrm{BMI} \geq 25[35,36]$, all reported rates were directly standardized to the European Standard Population in order to take account of the different age and gender composition of migrants and Swiss nationals [37]. The weighted, age- and gender-adjusted rates cover the migrant and Swiss population aged 17 64 years. 


\subsection{Statistical Analysis}

We used STATA for all statistical analyses. We report odds ratios (OR) for different nationalities from multivariate logistic regression models adjusting for age, gender, SES, and dwelling zone. We also report corresponding 95\% confidence intervals (CI) and p-values. To incorporate information on the appropriate weights and sampling units for correct variance estimation, all statistical analyses were carried out using STATA's command for complex surveys (svy prefix). Statistical significance was established at $\mathrm{p} \leq 0.05$.

\section{RESULTS}

We found different prevalence rates of normal weight, overweight and obesity between migrants and nationals of Switzerland (Table 2): while $69.0 \%$ of Swiss nationals aged 17 - 64 years had normal weight, $73.7 \%$ of German nationals had normal weight. The respective prevalence rates of normal weight for all other migrant groups were lower: Portugal 53.9\%, Turkey 49.9\%, Serbia $45.6 \%$, Kosovo $43.6 \%$ and Italy $50.2 \%$. Compared with Swiss nationals, all migrants - with the exception of German nationals - had higher prevalence rates of overweight and obesity.

Multivariate analysis adjusting for age, gender, SES and dwelling zone confirmed most of these initial results (Table 3). Compared with Swiss nationals, the odds of being obese $(\mathrm{BMI} \geq 30)$ was 1.97 times higher for Turkish nationals. Similarly, we found that the odds of being obese were 1.73 times higher for Kosovan nationals and 3.42 times higher for people from Serbia. The chance of being obese was not statistically different between Swiss nationals and those from Portugal, Italy, and Germany. With the exception of German nationals, we found that the chance of being overweight or obese (BMI $\geq 25)$ was higher for migrants than for Swiss nationals. The respec- tive odds were 1.54 times higher for nationals from Portugal, 2.05 times higher for those from Turkey, 2.67 times higher for those from Serbia, 2.68 times higher for those from Kosovo, and 2.16 times higher for nationals from Italy.

The odds of being obese $(\mathrm{OR}=1.04)$ or overweight or obese $(\mathrm{OR}=1.05)$ increased with age. Furthermore, we found that women were less likely to be obese $(\mathrm{OR}=$ $0.81)$ or to have a BMI greater or equal to $25(\mathrm{OR}=0.39)$ than men. Education was also significantly associated with body weight status. Subjects with secondary or university degree were generally less likely to be above normal weight than those with basic education. These results were especially pronounced for the obesity group. Subjects with a university degree were much less likely to be obese than those with basic education $(\mathrm{OR}=0.38)$. With regard to their weight status, economically active subjects did not differ from subjects who were not economically active. The chance of being overweight or obese was smaller for subjects who lived in more favourable housing situations $(\mathrm{OR}=0.94)$. However, the average number of rooms per person was not significantly associated with obesity. Similarly, we found that the odds of being overweight or obese are 1.25 times higher for rural dwellers than for urban dwellers, whereas the odds of being obese are not statistically different between those two groups.

Several studies show that migrants often adopt the dietary practices of the host country [30-33] and that their risk of obesity and overweight increases with increasing duration of residence [10,38]. Consequently, migrants in Switzerland may also be influenced by dietary acculturation. In order to control for potential acculturation effects, length of time in Switzerland (years) was added as a covariate to the model discussed above and the model was re-estimated using migrant data only. However, length of time in Switzerland had no statistically

Table 2. Adjusted BMI classification of subjects aged 17 - 64 years by nationality ${ }^{\mathrm{a}}$.

\begin{tabular}{ccccccc}
\hline \multirow{2}{*}{$\mathrm{n}=14,637$} & \multicolumn{2}{c}{ Normal weight $^{\mathrm{b}}$} & \multicolumn{2}{c}{ Overweight $^{\mathrm{b}}$} & \multicolumn{2}{c}{ Obese $^{\mathrm{b}}$} \\
\cline { 2 - 7 } & $\%$ & $95 \% \mathrm{CI}^{\mathrm{c}}$ & $\%$ & $95 \% \mathrm{CI}^{\mathrm{c}}$ & $\%$ & $95 \% \mathrm{CI}^{\mathrm{c}}$ \\
\hline Portugal & 53.9 & $47.7,60.1$ & 32.7 & $26.8,39.1$ & 13.4 & $9.8,18.1$ \\
Turkey & 49.9 & $43.4,56.4$ & 33.4 & $27.7,39.7$ & 16.7 & $11.8,23.3$ \\
Serbia & 45.6 & $38.6,52.8$ & 31.4 & $25.2,38.2$ & 23.0 & $17.2,30.1$ \\
Kosovo & 43.6 & $36.7,50.7$ & 42.0 & $34.6,49.7$ & 14.4 & $9.8,20.8$ \\
Germany & 73.7 & $66.2,80.1$ & 22.4 & $16.5,29.6$ & 3.9 & $1.9,7.8$ \\
Italy & 50.2 & $45.5,57.9$ & 38.7 & $31.5,46.5$ & 11.1 & $8.0,15.2$ \\
Switzerland & 69.0 & $67.9,70.0$ & 24.4 & $23.4,25.4$ & 6.6 & $6.1,7.2$
\end{tabular}

${ }^{\mathrm{a}}$ Data was weighted using the Swiss Migrant Health Survey 2010/Swiss Health Survey 2007 weights and adjusted for age and gender; ${ }^{\mathrm{b}}$ Normal weight: BMI < 25 ; overweight: $25 \leq \mathrm{BMI}<30$; obese: $\mathrm{BMI} \geq 30$; ${ }^{\mathrm{c}} 95 \% \mathrm{CI}$ : $95 \%$ confidence interval. 
Table 3. Multivariate logistic regression of factors associated with weight status, subjects aged 17 - 64 years ${ }^{\mathrm{a}}$.

\begin{tabular}{|c|c|c|c|c|c|c|}
\hline \multirow{2}{*}{$\mathrm{n}=14,637$} & \multicolumn{3}{|c|}{ Obesity $^{\mathrm{b}}$} & \multicolumn{3}{|c|}{ Overweight \& obesity ${ }^{\mathrm{b}}$} \\
\hline & $\mathrm{OR}^{\mathrm{c}}$ & $\mathrm{p}$ value & $95 \% \mathrm{CI}^{\mathrm{d}}$ & $\mathrm{OR}^{\mathrm{c}}$ & $\mathrm{p}$ value & $95 \% \mathrm{CI}^{\mathrm{d}}$ \\
\hline \multicolumn{7}{|l|}{ Nationality } \\
\hline Switzerland & 1.00 & \multicolumn{2}{|c|}{ Reference } & 1.00 & \multicolumn{2}{|c|}{ Reference } \\
\hline Portugal & 1.47 & 0.091 & $0.94,2.31$ & 1.54 & 0.007 & $1.13,2.11$ \\
\hline Turkey & 1.97 & 0.003 & $1.26,3.07$ & 2.05 & 0.000 & $1.50,2.78$ \\
\hline Serbia & 3.42 & 0.000 & $2.28,5.12$ & 2.67 & 0.000 & $1.93,3.68$ \\
\hline Kosovo & 1.73 & 0.021 & $1.09,2.74$ & 2.68 & 0.000 & $2.01,3.56$ \\
\hline Germany & 0.65 & 0.258 & $0.30,1.38$ & 0.78 & 0.158 & $0.55,1.10$ \\
\hline Italy & 1.40 & 0.087 & $0.95,2.06$ & 2.16 & 0.000 & $1.54,3.02$ \\
\hline Age (years) & 1.04 & 0.000 & $1.03,1.05$ & 1.05 & 0.000 & $1.04,1.05$ \\
\hline \multicolumn{7}{|l|}{ Gender } \\
\hline Male & 1.00 & \multicolumn{2}{|c|}{ Reference } & 1.00 & \multicolumn{2}{|c|}{ Reference } \\
\hline Female & 0.81 & 0.013 & $0.68,0.96$ & 0.39 & 0.000 & $0.35,0.43$ \\
\hline \multicolumn{7}{|l|}{ Education } \\
\hline Basic & 1.00 & \multicolumn{2}{|c|}{ Reference } & 1.00 & \multicolumn{2}{|c|}{ Reference } \\
\hline Secondary & 0.63 & 0.000 & $0.50,0.81$ & 0.72 & 0.000 & $0.60,0.86$ \\
\hline University & 0.38 & 0.000 & $0.28,0.52$ & 0.61 & 0.000 & $0.50,0.74$ \\
\hline \multicolumn{7}{|l|}{ Economically active } \\
\hline No & 1.00 & \multicolumn{2}{|c|}{ Reference } & 1.00 & \multicolumn{2}{|c|}{ Reference } \\
\hline Yes & 0.91 & 0.317 & $0.77,1.09$ & 1.14 & 0.054 & $1.00,1.30$ \\
\hline Housing situation (rooms/person) & 0.95 & 0.259 & $0.87,1.04$ & 0.94 & 0.019 & $0.89,0.99$ \\
\hline \multicolumn{7}{|l|}{ Dwelling zone } \\
\hline Urban dweller & 1.00 & \multicolumn{2}{|c|}{ Reference } & 1.00 & \multicolumn{2}{|c|}{ Reference } \\
\hline Rural dweller & 1.09 & 0.364 & $0.91,1.30$ & 1.25 & 0.000 & $1.12,1.39$ \\
\hline
\end{tabular}

${ }^{\mathrm{a}}$ Data was weighted using the Swiss Migrant Health Survey 2010/Swiss Health Survey 2007 weights and adjusted for age and gender; ${ }^{\mathrm{b}}$ Obesity: BMI $\geq 30$; overweight \& obesity: BMI $\geq 25$; ${ }^{\mathrm{c}} \mathrm{OR}$ : odds ratio; ${ }^{\mathrm{d}} 95 \% \mathrm{CI}$ : $95 \%$ confidence interval.

significant association with weight status (results not shown).

\section{DISCUSSION}

So far, population-based studies of the prevalence of overweight and obesity in Switzerland have been based mainly on data of the SHS [28]. However, the SHS data have limitations with regard to the study of migrants. First, interviews are only carried out in German, French and Italian. Second, the sampling process does not include any migrant-specific characteristics, e.g. country of origin. Consequently, the SHS data potentially favours well-integrated, well-educated and well-assimilated migrants and potentially omits vulnerable groups of migrants. The present study attempted to minimize selection bias by pooling data from the SMHS 2010 with data from the SHS. Since all interviews of participants in the pooled sample were conducted in their respective native langue, selection bias due to insufficient language skills has been mitigated.

Compared to Swiss nationals, migrants from Portugal, Turkey, Serbia, Kosovo and Italy had a higher risk of overweight or obesity as compared to normal weight. In contrast, German and Swiss nationals did not significantly differ in their weight status. This finding is in 
agreement with previous studies which studied migrants in Austria and Switzerland [25,26,28]. However, these studies were referring to nationals of the former Republic of Yugoslavia and were not able to differentiate between Serbs and Kosovans.

Similarly, studies reported that overweight is more common among Turkish migrants as compared to the Dutch or Swedish population $[14,16]$.

The highest risk of overweight/obesity was found for migrants from the Kosovo and Serbia while migrants from Serbia had the highest risk of obesity. German and Portuguese nationals always exhibited the lowest risk of overweight and obesity with regard to all other nonSwiss nationals and Turkish nationals were in-between Portuguese nationals and nationals form Serbia and Kosovo. Substantial differences in the risk of over-weight/ obesity and obesity exist between Swiss nationals and migrants which cannot be attributed to age, gender, socio-economic status, dwelling zone or differences in the demographic structure of the migrant and host population since we adjusted for these factors. Moreover our results suggest that differences in weight status between migrant groups and host population may be quite persistent. Unlike many other studies [13,27,39-41], we did not find that acculturation (length of residence) was significantly associated with weight status. That is, migrants in Switzerland seem to preserve their dietary practices.

This study has several limitations. First, data on BMI is derived from self-reported weight and height; respondents tend to overestimate their height and underestimate their weight, leading to under-reporting of BMI values $[42,43]$. Second, the limitations of the SMHS data did not allow a detailed investigation of the sources which structured the differences in the reported odds of overweight and obesity. Future studies may therefore want to focus on differences in dietary intake or food preferences between migrants and host country population.

In sum, our findings suggest that the risk of overweight and obesity among migrants from Portugal, Turkey, Serbia, Kosovo and Italy is higher as compared to Swiss nationals. Furthermore the risk of overweight and obesity is also substantially higher for persons with low education levels. Preventive strategies and initiatives should take into account the specific needs of migrants and individuals with low education, i.e. flyers and media messages should be translated into the native languages of the most prevalent migrant groups and the central messages should be clear and easy to understand.

\section{ACKNOWLEDGEMENTS}

This study was supported by the Swiss Federal Office of Public Health and the Swiss Federal Office for Migration; grant number
09.005923/704.0001/-330. There is no conflict of interest.

\section{REFERENCES}

[1] Arnlov, J., Sundstrom, J., Ingelsson, E. and Lind, L. (2011) Impact of BMI and the metabolic syndrome on the risk of diabetes in middle-aged men. Diabetes Care, 34, 61-65. doi:10.2337/dc10-0955

[2] Suka, M., Miwa, Y., Ono, Y. and Yanagisawa, H. (2011) BMI, waist circumference, and clustering of cardiovascular risk factors in Japanese adults. Environmental Health and Preventive Medicine, 16, 90-96. doi:10.1007/s12199-010-0169-7

[3] Denisov, L.N., Nasonova, V.A., Koreshkov, G.G. and Kashevarova, N.G. (2010) Role of obesity in the development of osteoarthrosis and concomitant diseases. Terapevticheski Arkhiv, 82, 34-37.

[4] Hsu, H.S., Liu, C.S., Pi-Sunyer, F.X., Lin, C.H., Li, C.I., Lin, C.C., Li, T.C. and Lin, W.Y. (2011) The associations of different measurements of obesity with cardiovascular risk factors in Chinese. European Journal of Clinical Investigation, 41, 393-404.

doi:10.1111/j.1365-2362.2010.02421.x

[5] Yatsuya, H., Toyoshima, H., Yamagishi, K., Tamakoshi, K., Taguri, M., Harada, A., Ohashi, Y., Kita, Y., Naito, Y., Yamada, M., et al. (2010) Body mass index and risk of stroke and myocardial infarction in a relatively lean population: Meta-analysis of 16 Japanese cohorts using individual data. Circulation Cardiovascular Quality and Outcomes, 3, 498-505.

[6] WHO/FAO (2005) Fruit and vegetables for health. Report of a Joint FAO/WHO Workshop, 1-3 September 2004, Kobe.

[7] Caprio, S., Daniels, S.R., Drewnowski, A., Kaufman, F. R., Palinkas, L.A., Rosenbloom, A.L. and Schwimmer, J.B. (2008) Influence of race, ethnicity, and culture on childhood obesity: Implications for prevention and treatment. Obesity (Silver Spring), 16, 2566-2577. doi:10.1038/oby.2008.398

[8] Mejean, C., Traissac, P., Eymard-Duvernay, S., El Ati, J., Delpeuch, F. and Maire, B. (2007) Influence of socioeconomic and lifestyle factors on overweight and nutrition-related diseases among Tunisian migrants versus nonmigrant Tunisians and French. BMC Public Health, 7, 265. doi:10.1186/1471-2458-7-265

[9] Faeh, D., Braun, J. and Bopp, M. (2011) Prevalence of obesity in Switzerland 1992-2007: The impact of education, income and occupational class. Obesity Reviews, 12, 151-166. doi:10.1111/j.1467-789X.2010.00793.x

[10] Singh, G.K., Siahpush, M., Hiatt, R.A. and Timsina, L.R. (2011) Dramatic increases in obesity and overweight prevalence and body mass index among ethnic-immigrant and social class groups in the United States, 1976-2008. Journal of Community Health, 36, 94-110. doi:10.1007/s10900-010-9287-9

[11] Brussaard, J.H., Van Erp-Baart, M.A., Brants, H.A., Hulshof, K.F. and Lowik, M.R. (2001) Nutrition and health among migrants in The Netherlands. Public Health Nutri- 
tion, 4, 659-664. doi:10.1079/PHN2001149

[12] Dijkshoorn, H., Nierkens, V. and Nicolaou, M. (2008) Risk groups for overweight and obesity among Turkish and Moroccan migrants in The Netherlands. Public Health, 122, 625-630. doi:10.1016/j.puhe.2007.08.016

[13] Van Loan, M.D., Schaefer, S.E., Salazar, M., Bruhn, C., Saviano, D. and Boushey, C. (2009) Influence of race, acculturation, and socioeconomic status on tendency toward overweight in Asian-American and Mexican-American early adolescent females. Journal of Immigrant and Minority Health, 11, 188-197. doi:10.1007/s10903-008-9150-6

[14] Wandell, P.E., Ponzer, S., Johansson, S.E., Sundquist, K. and Sundquist, J. (2004) Country of birth and body mass index: a national study of 2000 immigrants in Sweden. European Journal of Epidemiology, 19, 1005-1010. doi:10.1007/s10654-004-0159-4

[15] Wandell, P.E., Wajngot, A., De Faire, U. and Hellenius, M.L. (2007) Increased prevalence of diabetes among immigrants from non-European countries in 60-year-old men and women in Sweden. Diabetes \& Metabolism, 33, 30-36. doi:10.1016/j.diabet.2006.07.001

[16] Ujcic-Voortman, J.K., Bos, G., Baan, C.A., Verhoeff, A.P. and Seidell, J.C. (2011) Obesity and body fat distribution: Ethnic differences and the role of socio-economic status. Obesity Facts, 4, 53-60. doi:10.1159/000324555

[17] BFS (2010) Die bevölkerung der Schweiz 2009. Swiss Federal Statistical Office, Neuchâtel.

[18] Caperchione, C.M., Kolt, G.S. and Mummery, W.K. (2009) Physical activity in culturally and linguistically diverse migrant groups to Western society: A review of barriers, enablers and experiences. Sports Medicine, 39, 167-177. doi:10.2165/00007256-200939030-00001

[19] Ceballos, N. and Czyzewska, M. (2010) Body image in Hispanic/Latino vs European American adolescents: Implications for treatment and prevention of obesity in underserved populations. Journal of Health Care for the Poor and Underserved, 21, 823-838. doi:10.1353/hpu.0.0333

[20] Kolcic, I. and Polasek, O. (2009) Healthy migrant effect within Croatia. Collegium Antropologicum, 33, 141-145.

[21] Liu, J.H., Probst, J.C., Harun, N., Bennett, K.J. and Torres, M.E. (2009) Acculturation, physical activity, and obesity among Hispanic adolescents. Ethnic Health, 14, 509-525. doi:10.1080/13557850902890209

[22] Park, S.Y., Murphy, S.P., Sharma, S. and Kolonel, L.N. (2005) Dietary intakes and health-related behaviours of Korean American women born in the USA and Korea: The multiethnic cohort study. Public Health Nutrition, 8, 904-911. doi:10.1079/PHN2005740

[23] Olvera, N., Suminski, R. and Power, T.G. (2005) Intergenerational perceptions of body image in Hispanics: Role of BMI, gender, and acculturation. Obesity Research, 13, 1970-1979. doi:10.1038/oby.2005.242

[24] Nicolaou, M., Doak, C.M., Van Dam, R.M., Brug, J., Stronks, K. and Seidell, J.C. (2009) Cultural and social influences on food consumption in Dutch residents of Turkish and Moroccan origin: A qualitative study. Jour- nal of Nutrition Education and Behavior, 41, 232-241. doi:10.1016/j.jneb.2008.05.011

[25] Kirchengast, S. and Schober, E. (2006) Migration as risk factor of overweight and adipositas in children and adolescents. Anthropologischer Anzeiger, 64, 411-421.

[26] Kirchengast, S. and Schober, E. (2006) To be an immigrant: A risk factor for developing overweight and obesity during childhood and adolescence? Journal of Biosocial Science, 38, 695-705. doi:10.1017/S0021932005027094

[27] Akresh, I.R. (2008) Overweight and obesity among foreign-born and US-born Hispanics. Biodemography and Social Biology, 54, 183-199.

[28] Marques-Vidal, P., Vollenweider, P., Waeber, G. and Paccaud, F. (2011) Prevalence of overweight and obesity among migrants in Switzerland: Association with country of origin. Public Health Nutrition, 14, 1-9.

[29] BFS (2010) Statistik der bevölkerung und der Haushalte (STATPOP). Swiss Federal Statistical Office, Neuchâtel.

[30] Sofianou, A., Fung, T.T. and Tucker, K.L. (2011) Differences in diet pattern adherence by nativity and duration of US residence in the Mexican-American population. Journal of the American Dietetic Association, 111, 1563-1569 e1562.

[31] Shin, C.N. and Lach, H. (2011) Nutritional issues of Korean Americans. Clinical Nursing Research, 20, 162-180. doi:10.1177/1054773810393334

[32] Neuhouser, M.L., Thompson, B., Coronado, G.D. and Solomon, C.C. (2004) Higher fat intake and lower fruit and vegetables intakes are associated with greater acculturation among Mexicans living in Washington State. Journal of the American Dietetic Association, 104, 51-57. doi:10.1016/j.jada.2003.10.015

[33] Gregory-Mercado, K.Y., Staten, L.K., Ranger-Moore, J., Thomson, C.A., Will, J.C., Ford, E.S., Guillen, J., Larkey, L.K., Giuliano, A.R. and Marshall, J. (2006) Fruit and vegetable consumption of older Mexican-American women is associated with their acculturation level. Ethnic Disease, 16, 89-95.

[34] Allison, P.D. (2001) Missing data. Sage, Thousand Oaks.

[35] Volken, T., Schaffert, R. and Ruesch, P. (2011) Need for weight management in Switzerland: Findings from National Blood Pressure Week 2009. BMC Public Health, 11, 1-9. doi:10.1186/1471-2458-11-473

[36] Scheider, H., Venetz, W. and Gallani Bernardo, C. (2009) Overweight and obesity in Switzerland. Part 1: Cost of burden of adult obesity in 2007. HealthEcon, Basel.

[37] Ahmad, O.B., Bosch-Pinto, C., Lopez, A.D., Murray, C. J., Lozano, R. and Inoue, M. (2001) Age standardization of rates: A new WHO standard. GPE Discussion Paper Series, 31. World Health Organization, Geneva.

[38] Oza-Frank, R., Roshania, R. and Narayan, K.M.V. (2008) Age at arrival and risk of obesity among us immigrants. Obesity, 16, 2669-2675. doi:10.1038/oby.2008.425

[39] Bennett, G.G., Wolin, K.Y., Askew, S., Fletcher, R. and Emmons, K.M. (2007) Immigration and obesity among lower income blacks. Obesity, 15, 1391-1394. doi:10.1038/oby.2007.166 
[40] Ahluwalia, I.B., Ford, E.S., Link, M. and Bolen, J.C. (2007) Acculturation, weight, and weight-related behaviors among Mexican Americans in the United States. Ethnic Disease, 17, 643-649.

[41] Fernandez, A., Wang, S.P., Quan, J.D. and Kanaya, A.M. (2011) Asian Americans and obesity in California: A protective effect of biculturalism. Journal of Immigrant and Minority Health, 13, 276-283. doi:10.1007/s10903-010-9426-5

[42] Faeh, D., Braun, J. and Bopp, M. (2009) Underestimation of obesity prevalence in Switzerland: Comparison of two methods for correction of self-report. Swiss Medical Weekly, 139, 752-756.

[43] Faeh, D., Marques-Vidal, P., Chiolero, A. and Bopp, M. (2008) Obesity in Switzerland: Do estimates depend on how body mass index has been assessed? Swiss Medical Weekly, 138, 204-210.

[44] Schuler, M., Dessemontet, P. and Joye, D. (2005) Die raumgliederung der schweiz. Swiss Federal Statistical Office, Neuchâtel. 